\title{
Child Psychosocial Adjustment and Parenting in Families Affected by Maternal HIV/AIDS
}

\author{
Tanya L. Tompkins \\ Linfield College \\ Gail E. Wyatt \\ University of California - Los Angeles
}

Follow this and additional works at: https://digitalcommons.linfield.edu/psycfac_pubs

Part of the Child Psychology Commons, and the Maternal and Child Health Commons

\section{DigitalCommons@Linfield Citation}

Tompkins, Tanya L. and Wyatt, Gail E., "Child Psychosocial Adjustment and Parenting in Families Affected by Maternal HIV/AIDS" (2008). Faculty Publications. Accepted Version. Submission 2.

https://digitalcommons.linfield.edu/psycfac_pubs/2

This Accepted Version is protected by copyright and/or related rights. It is brought to you for free via open access, courtesy of DigitalCommons@Linfield, with permission from the rights-holder(s). Your use of this Accepted Version must comply with the Terms of Use for material posted in DigitalCommons@Linfield, or with other stated terms (such as a Creative Commons license) indicated in the record and/or on the work itself. For more information, or if you have questions about permitted uses, please contact digitalcommons@linfield.edu. 
ORIGINAL PAPER

Child Psychosocial Adjustment and Parenting in Families Affected by Maternal HIV/AIDS

Tanya L. Tompkins • Gail E. Wyatt

Running head: Parenting, Child Adjustment, and Maternal HIV/AIDS

Tanya L. Tompkins

Department of Psychology, Linfield College, 900 S.E. Baker Street, A570, McMinnville, OR 97128

e-mail: <tatompki@linfield.edu>

Gail E. Wyatt

Department of Psychiatry and Biobehavioral Sciences, University of California, Los Angeles, Los Angeles, CA 


\begin{abstract}
Child adjustment and parenting were examined in 23 9-through 16-year-old youth from families affected by maternal HIV infection and 20 same-age peers whose mothers were not infected. Children whose mothers were seropositive reported significantly more externalizing problems. Infected mothers reported less age-appropriate supervision/monitoring relative to non-infected mothers. Better mother-child relationship quality and less impairment in parental supervision/monitoring of age-appropriate youth behaviors were associated with fewer externalizing difficulties among the HIV-positive group only. Similarly, only among HIV-infected mothers was refraining from engaging in inconsistent disciplinary tactics associated with lower reports of internalizing and externalizing problems. These data highlight the promise of programs targeting parenting skills to prevent or ameliorate child difficulties.
\end{abstract}

Keywords: Parenting $\bullet$ Parent-Child Relationship $\bullet$ HIV/AIDS $\bullet$ Child adjustment $\bullet$ Maternal Illness 
Introduction

Despite recent advances in medical treatment, the proportion of women living with HIV/AIDS continues to increase in the U.S. (CDC, 2002). Most often HIV-infected mothers are of childbearing age and are the sole caregivers for their children (Dorsey, Chance, Forehand, Morse, \& Morse, 1999). A disproportionate number of infected mothers are African-American or Hispanic and the majority of these families are living in poverty (Schuster et al., 2000). As these women face this chronic, stigmatizing, and ultimately fatal disease it is important to understand how maternal HIV infection, along with the high-risk context associated with infection, is related to their children's psychosocial adjustment. Relatively few empirical studies have examined the experience of parenting with HIV/AIDS and the complexities of family life in the shadow of a foreshortened future (Family Health Project Research Group, 1998; Forsyth, Damour, Nagler, \& Adnopoz, 1996; Rotheram-Borus, Flannery, Rice, \& Lester, 2005).

Although the experience of children and mothers affected by HIV infection may differ in important ways (e.g., ethnicity, experience of stigma) from families coping with other parental illnesses, the research literature examining the relationship between parental illness, more broadly, and child psychosocial functioning provides tentative support for the assumption that many different types of parental illness appear to be associated with poorer child functioning (e.g., Korneluk \& Lee, 1998). Similarly, studies that have investigated whether parental HIV/AIDS is associated with youth adjustment problems seem to suggest that non-infected children living in families affected by parental HIV/AIDS demonstrate higher rates of maladjustment relative to children living in families not coping with parental illness (Bauman, Camacho, Silver, Hudis, \& Draimin, 2002; Esposito et al., 1999; Forehand et al., 1997; Forehand 
et al., 1998; Forsyth et al., 1996; Lester, Stein, \& Bursch, 2003; Rotheram-Borus \& Stein, 1999). Several factors limit the ability to draw firm conclusions regarding the association between maternal HIV infection and child maladjustment. First, several studies (Bauman et al., 2002; Lester et al., 2003; Rotheram-Borus \& Stein, 1999) did not include a control group, making it difficult to determine whether the higher rates of problem behaviors were significantly higher than the norm for children of similar ages and backgrounds. Second, extant research represents a heterogeneous collection of studies regarding socioeconomic level, ethnic background, developmental level, disease progression, disclosure status, and area of functioning assessed. Because so few investigations have been conducted, in no cases have similar populations been studied by independent research groups. Finally, inconsistent results regarding the nature of psychosocial difficulties (i.e., internalizing problems such as depression and anxiety or externalizing difficulties such as aggression and conduct problems) have been obtained. Given the limited number of studies conducted, it is difficult to determine if and how maternal seropositivity influences child psychosocial adjustment. For example, it appears that adolescents whose mothers are HIV-infected tend to exhibit higher rates of externalizing behaviors, whereas younger children of seropositive parents may evidence higher rates of internalizing problems (Esposito et al., 1999; Forsyth et al., 1996; Forehand et al., 1997; Forehand et al., 1998; Forehand et al., 2002), of externalizing problems (Esposito et al., 1999; Forehand et al., 1998), or of both (Bauman et al., 2002; Forehand et al., 1998; Esposito et al., 1999). It is unclear, however, whether this pattern is due to sampling characteristics (i.e., mothers vs. fathers; child age), methodological differences (i.e., failing to measure multiple domains of child functioning and/or measuring them in different ways and from different sources), or some combination 
thereof.

Although recent research has suggested that disclosure of disease status may influence youth mental health, results have been mixed in terms of whether awareness is associated with higher (e.g., Lee \& Rotheram-Borus, 2002) or lower (e.g., Murphy, Marelich, \& Hoffman, 2002) rates of negative child/adolescent outcomes. For example, using the current sample of participants, Tompkins (in press) found no differences in child functioning between the $61 \%$ of the HIV-affected families whose children were aware of their mothers' illness and those who were not informed.

Also lacking is a clear understanding of how living with HIV influences parenting. Relatively few studies (Black, Nair, \& Harrington, 1994; Dutra et al., 2000; Forehand et al., 2002; Kotchick, et al., 1997; Rotheram-Borus, Robin, Reid, \& Draimin, 1998), many of them strictly qualitative in nature (e.g., Faithfull, 1997; Ingram \& Hutchingson, 2000), have explored the experience of mothering with a contagious, stigmatized, and terminal illness.

Although associations between parental illness and child adjustment have been demonstrated, the mechanisms by which illness relates to child functioning remain relatively unexplored. One potential pathway involves the disruption of effective parenting (e.g., Kotchick, et al., 1997). Other family stressors (e.g., divorce) have been recognized as negatively affecting parenting (e.g., Fauber, Forehand, Thomas, \& Wierson, 1990) and child adjustment (e.g., Amato \& Keith, 1991). In fact, parenting has been identified as a mediator of the relationship between other family stressors and child outcome (Conger et al., 1992; Fauber et al., 1990). Thus, it seems reasonable to assume that maternal HIV/AIDS could also serve to disrupt parenting. A substantial literature suggests that parenting is related to child adjustment (e.g., 
Patterson, DeBaryshe, \& Ramsey, 1989) and several studies have examined this association in ethnically diverse samples (e.g., Brody, Stoneman, \& Flor, 1995). Few studies, however, have investigated parenting and child adjustment within the context of maternal HIV/AIDS.

Generally, the presence of HIV/AIDS in families appears to impair parenting efforts, such that these mothers demonstrate poorer parent-child relationships and less behavioral monitoring (Bauman et al., 2002; Dutra et al., 2000). While parenting is associated with child adjustment in predictable directions, HIV does not appear to qualify the direction or strength of this link (Kotchick et al., 1997). Other research, however, suggests that seropositivity may be associated with increased involvement (Black et al., 1994) and greater parenting satisfaction (Tompkins, Henker, Whalen, Axelrod, \& Comer, 1999). Thus, there are mixed results regarding the relationship between parenting and child adjustment within the context of HIV/AIDS.

Given the limited and mixed information on non-infected children affected by maternal HIV/AIDS and the potential for such a potent stressor to negatively impact both child adjustment and parenting, the overall purpose of the current study is to replicate and extend previous work by examining multiple areas of child psychosocial functioning in a multi-ethnic sample of noninfected children. To minimize source error, child functioning was assessed by multiple informants. We hypothesized that children whose mothers are HIV-infected would show decreased competence and increased problem behaviors relative to children of non-infected mothers. Specific hypotheses regarding the predominant nature (i.e., internalizing or externalizing problems) were not advanced. Second, we hypothesized that HIV-positive mothers would show impairment in the quality of the parent-child relationship and a pattern of fewer positive and more negative parenting practices relative to non-infected mothers. Finally, we 
sought to clarify the relationship between seropositive mothers' parenting and child adjustment more fully by including exploratory analyses examining the moderating influence of HIV status.

\section{Method}

\section{Participants}

Participants in this study were 23 HIV-infected women and one of their non-infected 9to 16-year-old children and $20 \mathrm{HIV}$-seronegative women and one of their 9- to 16-year-old children. Attempts were made to recruit numbers of African-American, Hispanic, and Caucasian participants reflective of the larger U. S. population of infected women resulting in 18 AfricanAmerican (42\%), 19 Latina (44\%), and 6 European American (14\%) women being assessed.

To be eligible to participate, mothers had to be between 18 and 50 years of age and be the custodial parent of a non-infected, biological child who was 9 to 16 years of age. The oldest child in each family who was enrolled in a local school was recruited for participation. Only women who self-reported no intravenous drug use for a minimum of 6 months prior to entering the study were eligible to participate. Information from medical records of HIV-positive women was obtained in order to classify disease status according to CDC HIV-staging procedures. Because so few of the participants $(N=3)$ had an AIDS diagnosis, this group was collapsed with the symptomatic group $(N=11)$ and contrasted with HIV-positive mothers who were asymptomatic $(N=9)$. Because preliminary results revealed no significant differences between these two groups in any of the parenting or child adjustment variables, these groups were combined and contrasted with non-infected mothers. The sample characteristics of both groups and statistical comparisons are presented in Table 1.

\section{Procedure}


All participants were recruited from the greater Los Angeles area and had previously participated in the UCLA-Women and Family Project (WFP), a comprehensive, longitudinal study investigating psychosocial adjustment, risk behavior, and social contexts in a multi-ethnic sample of HIV-infected and non-infected women (see Wyatt \& Chin, 1999). Participants in the HIV-infected group and the matched (by ethnicity, age and gender of the child, maternal education and income) HIV-seronegative control group were recruited from a sub-sample of eligible participants (i.e., mothers) participating in the WFP.

Of 53 HIV-infected women from the WFP who were eligible to participate, 23 agreed to participate, while 30 were unable (i.e., 23 were unreachable, 3 moved, 2 died) or unwilling to participate (i.e., 2 declined). Of 35 HIV-negative women from the WFP who met eligibility criteria, 20 agreed to participate, while 15 declined or were otherwise unable to participate (i.e., 5 declined, 7 were unreachable, 2 moved, 1 lost custody of her children). Once the mother and child agreed to participate, the initial data collection session was scheduled following a brief phone screening designed to confirm eligibility.

All procedures were reviewed and approved by the Institutional Review Board (IRB). Written consent and verbal assent was obtained from mothers and children, respectively, following a thorough description of the study during the first session. Mother and child were interviewed separately. Those mothers who gave consent for teacher contacts $(N=41)$ were asked to provide the address and name of the child's teacher and written consent to release the child's school records to the project. Participants received compensation for their time ( $\$ 50$ per family per assessment session) at the completion of the interview. The second interview for HIV-infected participants and their children was conducted within two weeks of the first 
interview.

Because two types of interviews were administered (child and parent), two sets of interviewers were utilized. Given the relative advantages of employing ethnically matched interviewers in increasing rapport and trust (e.g., Brody et al., 1995), attempts at ethnic match for mother and/or child interviews were made. All Spanish-speaking mothers $(N=13)$ were interviewed by native Spanish-speaking, bilingual interviewers. Because the mother interviews inquired about personal issues relating to motherhood, only female interviewers were used. All materials, including consent and assent forms, were administered orally to all participants.

\section{Measures}

Efforts were made to employ well-standardized measures of parent, child, and family functioning, particularly those instruments that had been used with similar populations. Alpha coefficients were calculated for all measures. Although information from a variety of additional measures was obtained as part of the project, only the measures relevant to the current study are described below. The complete list of measures can be obtained from the first author.

Areas of interest included basic demographic information (e.g., mother age, child age, educational attainment, family structure, etc.), parenting, and child psychosocial functioning.

Parenting. Three dimensions of parenting were assessed: (1) mother-child relationship quality (2) parenting practices and (3) degree of routinization present in the household. Relationship quality was assessed by the short form of the Conflict Behavior Questionnaire (CBQ; Robin \& Foster, 1989) that consists of 20 dichotomous items inquiring about the quality of parent-child interactions. Each item was endorsed as true or false, with higher scores reflecting poorer relationship quality. The short-form total score correlates .96 with the sum of 
the two scales for the long form (Robin \& Foster, 1989). Both mother and child instruments yielded acceptable alpha coefficients in the current sample (.90 and .89 , respectively).

Parenting practices were assessed from the perspective of both mother and child as participants completed the Alabama Parenting Questionnaire (APQ; Frick, 1991). The 42-item APQ measures how typical are a variety of statements assessing involvement, positive parenting, poor supervision/monitoring, discipline, inconsistent discipline, and use of harsh discipline. Items are rated on a 5-point scale, ranging from 1 (never) to 5 (always). Across mother and child report, only the first three scales were found to have adequate reliability (involvement, positive parenting, and monitoring) for use in the present study, with alpha coefficients ranging from .80 to .85 . The inconsistent discipline scale demonstrated adequate reliability only for mothers $($ alpha $=.80)$.

The Family Routines Inventory (FRI; Jenson, James, Boyce, \& Hartnett, 1983), a 28-item measure, was used to assess consistency and organization of family routines. Mothers rated the items on a 4-point scale ranging from 0 (never) to 3 (daily) with higher scores reflecting more consistent family routines. Adequate psychometric data have been provided for this measure (Jensen et al., 1983). Reliability was found to be acceptable in the current sample (alpha $=.84$ ).

Child Psychosocial Adjustment. Two areas of children's psychosocial adjustment were examined: behavior problems and perceived competence. Given findings of low inter-informant agreement on child adjustment and the belief that different informants validly contribute different information (Ferdinand, van der Ende, \& Verhulst, 2004), all domains of child adjustment were assessed by multiple sources.

To assess behavior problems, mothers completed the Child Behavior Checklist (CBCL; 
Achenbach, 1991a), a well-standardized and reliable measure of children's behavior problems. The CBCL consists of 113 items describing problem behaviors that are rated on a 3-point scale ranging from 0 (not true) to 2 (very true or often true). Raw scores on the scale were converted to $\mathrm{T}$-scores based on age and gender norms with higher scores indicating more problematic behavior. Broadband categories of internalizing and externalizing behavior problems were the variables of interest in the study. Mean test-retest reliability is .87 and evidence for content and criterion validity has been established (Achenbach, 1991a). Teachers completed the Teacher Report Form (TRF; Achenbach \& Edelbrock, 1986), and children completed the Youth Self Report Form (YSR; Achenbach, 1991b), both parallel versions of the CBCL.

Mother and child reports of competence across different domains were assessed using the Parent's Rating Scale of Child's Actual Competencies (PRS; Harter, 1985) and the SelfPerception Profile for Children (SPPC; Harter, 1985), respectively. Additionally, teacher reports of competence were gathered employing a teacher version of the rating scale (TRS). Each item is scored from 1 (low competence) to 4 (high competence). Harter (1985) reported adequate reliability for the various scales across different samples. Only the scholastic, social, and behavioral domains were of interest in the current study. Alpha coefficients ranged from .68 to.89 for child, mother, and teacher reports, respectively.

\section{Results}

\section{Preliminary Analyses}

Preliminary analyses were conducted to see if child age or gender qualified the relationship between maternal HIV status and child functioning. To examine age, the sample was divided at the midpoint of the age range of participating children, a division that allowed 
comparison between pre-adolescent (9-12 year olds) and adolescent (13-16 year olds) children. In 2 (maternal HIV) X 2 (child gender) X 2 (child age) analyses of variance (ANOVAs), neither child age nor child gender interacted with HIV status to influence any of the child adjustment dependent variables, with the sole exception of children's reports of externalizing difficulties. A significant interaction between HIV status and child age was found for child-reported externalizing problems, $F(1,41)=9.07, p<.01$. Thus, child age was used as a covariate for all analyses involving self-reported externalizing problems. A similar analytic strategy was adopted to examine whether child age and gender qualified the relationship between maternal HIV status and parenting indicators. With the exception of mother's reports of monitoring, neither child age nor child gender interacted with HIV status to influence parenting. A significant interaction between HIV status and child age was found for mother-reported monitoring, $F(1,41)=9.12, p$ $<.01$. Thus, child age was used as a covariate for all analyses involving maternal monitoring. Similar analyses were conducted to determine if ethnicity qualified the relationship between HIV status and parenting or child adjustment. No significant interactions were found.

\section{Child Adjustment}

The means and standard deviations for each measure of child psychosocial adjustment for both the HIV-infected and non-infected groups are presented in Table 2. One-way ANOVAs and one-way analyses of covariance (ANCOVAs ) were conducted with maternal HIV status serving as the independent variable. Results indicated that children whose mothers were HIV infected reported having more externalizing problems, relative to children whose mothers were not infected, even when controlling for the effects of child age $F(1,41)=4.73, p<.05$. No significant between-group differences were detected for child self-reported social or cognitive 
competence, nor for self-reported internalizing difficulties. Neither mother nor teacher reports revealed group differences in child behavior problems, cognitive competence, or social competence.

\section{Parenting}

One-way ANOVAs and one-way analyses of covariance (ANCOVAs ) were conducted with maternal HIV status serving as the independent variable. Results indicated that HIVpositive mothers $(M=1.8, S D=0.6)$ reported significantly higher rates of poor monitoring relative to non-infected mothers $(M=1.5, S D=0.4)$, controlling for the effects of child age on maternal monitoring, $F(1,42)=4.69, p<.05$. Mothers who are HIV-positive also reported a trend toward poorer parent-child relationship quality $(M=5.6, S D=5.8)$ in comparison to noninfected mothers $(M=3.2, S D=3.1), F(1,42)=3.15, p<.10$.

Correlational analyses were conducted to evaluate the association between parenting and child psychosocial adjustment variables. As shown in Table 3, reports of a higher quality parentchild relationship were generally associated with lower levels of behavior problems and higher levels of social and cognitive competence, although results vary by informant. Apart from the internalizing domain, poorer maternal monitoring was associated with most areas of child psychosocial functioning. Positive parenting, maternal involvement, inconsistent disciplining, and family routinization were limited in their scope being associated with two or fewer domains and/or isolated to one reporter of psychosocial adjustment.

To examine whether maternal HIV status differentially influenced the relationship between parenting processes and child psychosocial adjustment, a series of hierarchical regression analyses were conducted which included HIV status, the particular parenting variable 
under consideration, and an interaction term between HIV status and each parenting variable as independent predictors of child adjustment. Analyses were conducted only for those variables which demonstrated zero-order relationships across domains and/or reporters. Consistent with Aiken and West (1991), prior to creating interaction terms, all continuous dependent and predictor variables were first centered to reduce multicollinearity. HIV status significantly influenced the strength of the relation between children's reports of mother child relationship quality and mothers' reports of child externalizing difficulties, $\Delta \mathrm{R}^{2}=.14, F_{\text {change }}(1,38)=7.92, p$ $<.01$, suggesting that HIV status was a significant moderator of the relationship between mother-child relationship and child externalizing problems. Inspection of this interaction revealed that child-reported relationship quality was not significantly associated with motherreported externalizing problems in non-infected families, $B=-.34, t(38)=-0.51, p>.05$, whereas a strong relationship existed between these two variables in families affected by maternal HIV/AIDS, $B=1.91, t(38)=4.42, p<.001$. Similarly, the interaction term between HIV status and mother-reported poor monitoring was significant, $\Delta \mathrm{R}^{2}=.07, F_{\text {change }}(1,38)=$ $4.50, p<.05$, suggesting that HIV status was a significant moderator of the relationship between monitoring and child externalizing symptoms. Inspection of this interaction revealed that mother-reported poor monitoring was not significantly associated with mother-reported externalizing problems in non-infected families, $B=3.63, t(38)=.67, p>.05$, whereas a strong relationship existed between these two variables in families affected by maternal HIV/AIDS, $B=$ $16.98, t(38)=5.27, p<.001$. Finally, the effects of inconsistent disciplining on mother-reported externalizing and internalizing problems varied according to maternal HIV status, $\Delta \mathrm{R}^{2}=.13$, $F_{\text {change }}(1,38)=8.47, p<.01, \Delta \mathrm{R}^{2}=.07, F_{\text {change }}(1,38)=4.84, p<.05$, respectively. Testing the 
significance of simple slopes revealed that mother-reported inconsistent parenting was not significantly associated with either mother-reported externalizing problems, $B=2.05, t(38)=$ $.76, p>.05$ or internalizing problems, $B=4.26, t(38)=1.76, p>.05$, in non-infected families. Conversely, strong relationships between these two variables in families affected by maternal HIV/AIDS were found for both externalizing, $B=12.65, t(38)=5.20, p<.001$ and internalizing, $B=11.39, t(38)=5.26, p<.001$, difficulties. Thus, it appears that these three aspects of parenting are more effective predictors of child problems in families affected by maternal HIV infection.

\section{Discussion}

Results lent partial support to the hypothesis that maternal HIV infection, along with the contextual antecedent and concomitant factors associated with infection, represents a stressor that may place non-infected youth at risk for psychosocial maladjustment. Specifically, children of HIV-positive mothers reported higher levels of externalizing problems, relative to children whose mothers were not infected. No group differences were clearly evident in other domains of child adjustment. The relationship between maternal HIV infection and child psychosocial adjustment appears to vary by informant, with adjustment differences found only with child self report. This finding is inconsistent with earlier results suggesting impairment across multiple domains when both parent and child reporters are included (Esposito et al., 1999; Forehand et al., 1998) and across informants for internalizing problems (Forsyth et al., 1996). The pattern, however, is congruent with findings from the general parental illness literature suggesting that ill parents may not perceive child distress (e.g., Welch, Wadsworth, \& Compas, 1996).

There are many reasons why mothers coping with a serious illness might either fail to 
detect or choose to underreport child problems. One possibility is that maternal reports accurately reflect fewer problems at home. Another potential explanation is that some of these mothers, as a result of impairment associated with worsening physical symptoms and/or medication side effects, may be less involved in children's day-to-day care and, therefore, be less aware of potential child difficulties. Still another, is that mothers minimize the extent or nature of the problems owing to guilt or denial associated with past behaviors or worsening illness. Although the pattern of means amongst child, mother and teacher reports of child functioning offer tentative support for some of these explanations, the small sample size and low power suggest caution in drawing conclusions. A last explanation, discussed more extensively below, is that the period of acute maladjustment may have passed for some families.

Findings of higher self-reported externalizing problems among children whose mothers are seropositive mirror past findings of heightened levels of externalizing difficulties among noninfected youth affected by parental HIV/AIDS (Forehand et al., 1998; Rotheram-Borus et al., 1998). They are somewhat discrepant, however, with findings suggesting more difficulties of an internalizing nature (Forehand et al., 1997; 1998; Forsyth et al., 1996) and with results revealing elevated rates of both externalizing and internalizing problems (Esposito et al., 1999; Forehand et al., 1998) among this population. These differences may be explained, in part, by the normative tendency for externalizing risk behaviors to increase with age (CDC, 1996); the current sample included children who were relatively older than the participants in other investigations (e.g., Esposito et al., 1999; Forehand et al., 1998; Forsyth et al., 1996).

Additionally, rates of disclosure, length of time since diagnosis, length of time between disclosure and assessment, all represent factors that varied across studies and may have 
influenced the relationship between maternal HIV status and child adjustment. For example, in comparison to the FHP sample (Forehand et al., 1998), the women participating in the current study had more likely disclosed to their children (61\% vs. $30 \%)$, had been diagnosed for a longer period of time (5.4 years vs. approximately 3 years), and, their children had, on average, known about their mother's diagnosis for a longer period of time (3.7 years vs. 2.3 years). Thus, it may be that disruptions across multiple domains represent a relatively short-term accommodation to the diagnosis and its associated sequelae. Such conclusions, however, await the recruitment of a large sample of children and adolescents who are followed over time. Longitudinal investigations are necessary in order to disentangle the influence of these multiple factors and will be critical in understanding which short-term reactions may be associated with longer-term deleterious effects and thus, in need of early intervention. Such clarification seems particularly salient within the context of increased access to more effective treatments that may lessen symptoms, lengthen symptom-free periods, and alter prognostic perceptions of the diagnosis.

Results from this multi-ethnic sample highlight the importance, for child psychosocial adjustment, of the mother-child relationship, of monitoring of children's behavior outside the home, and of providing consistent routines within the home. Results were congruent with other studies by Forehand and colleagues (e.g., Kotchick et al., 1997) in suggesting that these aspects of the parenting role are critical in their influence on child adjustment. In the current study, maintenance of consistent family routines was also associated with fewer behavioral difficulties and higher levels of cognitive competence. Other aspects of parenting (involvement, positive parenting) were linked with better social and cognitive competence. Thus, the current results support research that suggests that authoritative parenting is associated with healthy child and 
adolescent adjustment across ethnically and socioeconomically diverse populations (Steinberg, Mounts, Lamborn, \& Dornbusch, 1991).

Between-group comparisons revealed that mothers who are HIV-positive reported decrements in both relationship quality and monitoring, relative to non-infected mothers. These two aspects of parenting were strongly associated with child psychosocial adjustment, particularly among HIV-positive mothers, and appeared to be at least somewhat disrupted by maternal HIV infection. In fact, these differences in parenting may have partially accounted for higher levels of child externalizing difficulties found among children whose mothers were infected, relative to those whose mothers were healthy. As suggested by Kotchick et al. (1997), maternal HIV may exert a direct effect on parenting such that lower levels of adequate parenting account for poorer child adjustment. HIV may also disrupt parenting and child adjustment through activation of negative family processes (e.g., maternal depression, stigmatization, heightened parenting stress). Again, larger samples are needed for adequate tests of alternate models for the influence of maternal HIV infection on child psychosocial adjustment. There are undoubtedly multiple pathways through which HIV exerts its influence, involving a confluence of vulnerabilities and/or severe disruption in one aspect of parenting or family life.

Contrary to previous findings suggesting that HIV does not generally modify the relationship between parenting and child adjustment (Kotchick et al., 1997), the current results suggest that maternal HIV status may play a qualifying role in the relationship between several parenting processes and child adjustment. Other family stressors, such as divorce (Fauber et al., 1990), have been found to negatively impact child adjustment directly (i.e., through disruption of parenting) and indirectly (i.e., variance of associated factors reduces the predictive power of 
parenting). In the current sample, however, the presence of HIV infection seemed to heighten the predictive power of parenting, wherein the mother-child relationship, poor monitoring, and inconsistent disciplining were more strongly associated with child maladjustment among families facing maternal HIV infection. Perhaps this is not altogether surprising considering the increased importance placed on the mothering role that was anecdotally apparent during the interview and documented in past research (e.g., Black et al., 1994; Tompkins et al., 1999). These findings suggest that prevention and intervention programs that focus on improving: the mother-child relationship, behavioral monitoring of child behavior, and consistent discipline in response to child transgressions, are needed to effectively targeting child psychosocial maladjustment among non-infected youth affected by maternal HIV. Additionally, given that moderation was most apparent when mothers were reporting on both parenting and child adjustment, assessment with non-infected families should extend beyond maternal reports of child and family functioning.

Several limitations of the current study must be noted. First, the inclusion of children from a wide range of developmental levels made it difficult to interpret the discrepancies among the few extant studies of the pervasiveness and nature of child maladjustment in youth affected by HIV/AIDS. While the inclusion of different age groups may operate to increase the external validity of this study, future studies that include more substantial numbers of child participants within different age groups would permit exploration of effects as a function of age. A second limitation involves the cross-sectional, correlational, and descriptive nature of the research design that precludes any conclusions about directions of influence or causality. For example, differences in child adjustment and/or parenting between infected and non-infected groups 
cannot be solely or even specifically attributable to HIV infection. Needed are large-scale, longitudinal studies that follow newly diagnosed or high risk mothers and their children in order to examine child adjustment and parenting as they unfold and interact over time. Such investigations promise not only to enhance our understanding of the possible mechanisms through which HIV infection exerts its effects, but also to provide clarity regarding timing issues (e.g., whether child problems precede or follow maternal diagnosis) and the dismantling of packages of adversity confronting these families. Additionally, including a group experiencing a different family stressor would enable researchers to examine issues of specificity of risk (see McMahon, Grant, Compas, Thurm, \& Ey, 2003 for a thoughtful discussion of this issue). Third, a major drawback of the current investigation was the small sample size that limited statistical power and severely constrained the examination of complex multivariate relationships. Given that many analyses involved so few participants, results should be considered preliminary. Future research should not only seek to recruit generally larger samples, but should strive to include sufficient numbers of participants in groups of interest in order to be able to understand cultural, economic, and developmental differences that may underlie group differences. Finally, the current research relied solely on self-report data, and as such, the possibility that common method variance accounts for some of the results cannot be ruled out.

The aforementioned limitations should be considered within the context of the study's strengths. First, the inclusion of a matched control group allowed relationships between maternal HIV infection, child functioning, and parenting to be examined against a backdrop of the broader environmental context. Second, both child competence and emotional/behavioral difficulties were assessed, important features in that each dimension contributes to a fuller 
understanding of child functioning. Given findings that suggest that competence and problem behaviors may be unrelated, particularly among highly-stressed groups, inclusion of multiple domains of child adjustment seems paramount (Garmezy, Masten, \& Tellegen, 1984).

Finally, this study adds to the literature on parenting and child functioning within the context of HIV-infection, a timely issue given the growing rates of infection among women of childbearing age and the relative neglect of HIV-positive women and their non-infected children. Given the inclusion of family process variables (e.g., parent-child relationship, routinization) that are amenable to change, it is hoped that results will be useful in informing prevention and intervention efforts with these families.

\section{References}

Achenbach, T. M. (1991a). Manual for the Child Behavior Checklist 4-18 and 1991 profile. Burlington, VT: University of Vermont Department of Psychiatry.

Achenbach, T. M. (1991b). Manual for the Youth Self-Report and 1991 profile. Burlington, VT: University of Vermont Department of Psychiatry.

Achenbach, T. M., \& Edelbrock, C. S. (1986). Manual for the Teacher Report Form of the child behavior profile. Burlington, VT: University of Vermont Department of Psychiatry.

Aiken, L. S., \& West, S. G. (1991). Multiple regression: Testing and interpreting interactions. Thousand Oaks, CA: Sage.

Amato, P.R., \& Keith, B. (1991). Parental divorce and the well-being of children: A meta-analysis. Psychological Bulletin, 110, 26-46.

Bauman, L. J., Camacho, S., Silver, E. J., Hudis, J., \& Draimin, B. (2002). Behavioral 
Child Psychosocial Adjustment 22

problems in school-aged children of mothers with HIV/AIDS. Clinical Child Psychology and Psychiatry, 7, 39-54.

Black, M. M., Nair, P., \& Harrington, D. (1994). Maternal HIV infection: Parenting and early child development. Journal of Pediatric Psychology, 19, 595-616.

Brody, G. H., Stoneman, Z., \& Flor, D. (1995). Linking family processes and academic competence among rural African American youths. Journal of Marriage and the Family, $57,567-579$.

Centers for Disease Control and Prevention (1996). Youth risk behavior surveillance in the United States, 1995. Morbidity and mortality weekly report, 45,_(SS-4).

Centers for Disease Control and Prevention (2002). HIV/AIDS surveillance report, 14, 1-48. Atlanta, GA: Author.

Compas, B. E., Worsham, N. L., Ey, S., \& Howell, D. C. (1996). When mom or dad has cancer: II. Coping, cognitive appraisals, and psychological distress in children of cancer patients. Health Psychology, 15, 167-175.

Conger, R. D., Conger, K. J., Elder, G. H., Jr., Lorenz, F. O., Simons, R. L., \& Whitbeck, L. B. (1992). A family process model of economic hardship and adjustment of early adolescent boys. Child Development, 63, 526-541.

Dorsey, S., Chance, M. W., Forehand, R., Morse, E., \& Morse, P. (1999). Children whose mothers are HIV infected: Who resides in the home and is there a relationship to child psychosocial adjustment? Journal of Family Psychology, 13, 103-117.

Dutra, R., Forehand, R., Armistead, L., Brody, G., Morse, E., Morse, P. S., \& Clark, L. (2000). Child resiliency in inner-city families affected by HIV: The role of family variables. 
Behavior Research and Therapy, 38, 471-486.

Esposito, S., Musetti, L., Musetti, M. C., Corbella, S., Massironi, E., Marchisio, P., et al. (1999). Behavioral and psychological disorders in uninfected children aged 6 to 11 years born to Human Immunodeficiency Virus-seropositive mothers. Developmental and Behavioral Pediatrics, 20, 411-417.

Faithfull, J. (1997). HIV-positive and AIDS-infected women: Challenges and difficulties of mothering. American Journal of Orthopsychiatry, 67, 144-151.

Family Health Project Research Group. (1998). The Family Health Project: A multidisciplinary longitudinal investigation of children whose mothers are HIV infected. Clinical Psychology Review, 18, 839-856.

Fauber, R., Forehand, R., Thomas, A., \& Wierson, M. (1990). A mediational model of the impact of marital conflict on adolescent adjustment in intact and divorced families: The role of disrupted parenting. Child Development, 61, 1112-1123.

Ferdinand, R. F., van der Ende, J., \& Verhulst, F. C. (2004). Parent-adolescent disagreement regarding psychopathology in adolescents from the general population as a risk factor for adverse outcome. Journal of Abnormal Psychology, 113, 198-206.

Forehand, R., Armistead, L., Weirson, M., Brody, G. H., Neighbors, B., Hannon, J., \& the PAC Project. (1997). Hemophilia and AIDS in married men: Functioning of family members. American Journal of Orthopsychiatry, 67, 470-484.

Forehand, R., Jones, D. J., Kotchick, B. A., Armistead, L., Morse, E., Morse, P. S. et al. (2002). Non-infected children of HIV-infected mothers: A 4-year longitudinal study of child psychosocial adjustment and parenting. Behavior Therapy, 33, 579-600. 
Forehand, R., Steele, R., Armistead, L., Morse, E., Simon, P., \& Clark, L. (1998). The family health project: Psychosocial adjustment of children whose mothers are HIV infected. Journal of Consulting and Clinical Psychology, 66, 512-520.

Forsyth, B.W. C., Damour, L., Nagler, S., \& Adnopoz, J. (1996). The psychological effects of parental human immunodeficiency virus infection on uninfected children. Archives of Pediatric Adolescent Medicine, 150, 1015-1020.

Frick, P. J. (1991). The Alabama parenting questionnaire. Unpublished instrument. University of Alabama.

Garmezy, N., Masten, A. S., \& Tellegen, A. (1984). The study of stress and competence in children: A building block for developmental psychopathology. Child Development, 55, 97-111.

Harter, S. (1985). Manual for the Self-Perception Profile for Children. Denver, CO: University of Denver.

Ingram, D., \& Hutchinson, S. A. (2000). Double binds and the reproductive and mothering experiences of HIV-positive women. Qualitative Health Research, 10, 117-132.

Jensen, E. W., James, S. A., Boyce, W. T., \& Hartnett, S. A. (1983). The Family Routines Inventory: Development and validation. Social Science Medicine, 17, 201-211.

Korneluk, Y. G., \& Lee, C. M. (1998). Children's adjustment to parental physical illness. Clinical Child and Family Psychology Review, 1, 179-193.

Kotchick, B. A., Forehand, R., Brody, G., Armistead, L., Morse, E., Simon, P., \& Clark, L. (1997). The impact of maternal HIV infection on parenting in inner-city AfricanAmerican families. Journal of Family Psychology, 11, 447-461. 
Kovacs, M. (1980/1981). Rating scales to assess depression in school-aged children. Acta Paedopsychiatricia, 46, 305-315.

Lee, M. L., \& Rotheram-Borus, M. J. (2002). Parents' disclosure of HIV to their children. AIDS, 16, 2201-2207.

Lester, P., Stein, J. A., \& Bursch, B. (2003). Developmental predictors of somatic symptoms in adolescents of parents with HIV: A 12-month follow-up. Developmental and Behavioral Pediatrics, 24, 242-250.

McMahon, S. D., Grant, K. E., Compas, B. E., Thurm, A. E., \& Ey, S. (2003). Stress and psychopathology in children and adolescents: Is there evidence of specificity? Journal of Child Psychology and Psychiatry, 44, 107-133.

Murphy, D. A., Greenwell, L., Mouttapa, M., Brecht, M., \& Schuster, M. A. (2006). Physical health of mothers with HIV/AIDS and the mental health of their children. Journal of Developmental \& Behavioral Pediatrics, 27, 386-395.

Murphy, D. A., Marelich, W.D., \& Hoffman, D. (2002). A longitudinal study of the impact on young children of maternal HIV serostatus disclosure. Clinical Child Psychology and Psychiatry, 7, 55-70.

Patterson, G. R., DeBaryshe, B. D., \& Ramsey, E. (1989). A developmental perspective on antisocial behavior. Special issue: Children and their development: Knowledge base, research agenda, and social policy application. American Psychologist, 44, 329-335.

Reynolds, C. R., \& Richmond, B. O. (1997). What I think and feel: A revised measure of the children's manifest anxiety. Journal of Abnormal Child Psychology, 25, 15-20.

Robin, A. L., \& Foster, S. (1989). Negotiating parent-adolescent conflict. New York, NY: 
Guilford Press.

Rotheram-Borus, M. J., Flannery, D., Rice, E., \& Lester, P. (2005). Families living with HIV. AIDS Care, 17, 978-987.

Rotheram-Borus, M. J., Robin, L., Reid, H. M., \& Draimin, B. H. (1998). Parent-adolescent conflict and stress when parents are living with AIDS. Family Process, 37, 83-94.

Rotheram-Borus M. J., \& Stein, J. A. (1999). Problem behavior of adolescents whose parents are living with AIDS. American Journal of Orthopsychiatry, 69, 228-239.

Schuster, M. A., Kanouse, D. E., Morton, S. C., Bozzette, S. A., Miu, A., Scott, G. B. et al. (2000). HIV-infected parents and their children in the United States. American Journal of Public Health, 90, 201-219.

Steinberg, L., Mounts, N. S., Lamborn, S. D., \& Dornbusch, S. M. (1991). Authoritative parenting and adolescent adjustment across varied ecological niches. Journal of Adolescence, 1, 19-36.

Tompkins, T. L. (in press). Disclosure of maternal HIV status to children: To tell or not to tell... that is the question. Journal of Child and Family Studies.

Tompkins, T. L., Henker, B., Whalen, C. K., Axelrod, J., \& Comer, L. K. (1999). Motherhood in the context of HIV infection: Reading between the numbers. Cultural Diversity and Ethnic Minority Psychology, 5, 197-208.

Welch, A., Wadsworth, M., \& Compas, B. (1996). Adjustment of children and adolescents to parental cancer. Parents' and children's perspectives. Cancer, 77, 1409-1418.

Wyatt, G. E., \& Chin, D. (1999). HIV \& ethnic minority women, families, and communities: An overview. Cultural Diversity and Ethnic Minority Psychology, 5, 179-182. 
Table 1

Sample Characteristics of HIV-Infected and Non-infected Mothers

\begin{tabular}{llll} 
& \multicolumn{1}{c}{ M } & $\mathrm{F}^{\mathrm{a}}$ \\
\cline { 2 - 3 } Characteristics & HIV+ & HIV- & \\
\hline & & & Mothers \\
Mother Age (in years) & 38.33 & 40.44 & $1.10^{\mathrm{a}}$ \\
Ethnicity & & &
\end{tabular}

African-American

European-American

Latina

Education

Less than high school

High School or General Equivalency Diploma

Vocational or Associate of Arts degree

Some College (no degree)

College Degree

Yearly Income Level

Less than $\$ 15,000$

$\$ 15,000$ - \$29,999

$\$ 30,000$ - \$49,999

Over $\$ 50,000$
$\mathrm{F}^{\mathrm{a}}$

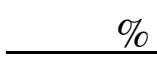

HIV+

HIV- $\chi^{2}$

$\begin{array}{ll}39 \% & 45 \% \\ 13 \% & 15 \% \\ 48 \% & 40 \%\end{array}$

2.07

$39 \% \quad 20 \%$

$9 \% \quad 15 \%$

$26 \% \quad 30 \%$

$13 \% \quad 20 \%$

$13 \% \quad 15 \%$

3.13

$30 \% \quad 15 \%$

$30 \% \quad 20 \%$

$22 \% \quad 30 \%$

$18 \% \quad 35 \%$ 
(Table 1 , continued)

Sample Characteristics of HIV-Infected and Non-infected Mothers

\begin{tabular}{|c|c|c|c|c|c|c|}
\hline \multirow[b]{2}{*}{ Characteristics } & \multirow{2}{*}{$\begin{array}{r}\mathrm{M} \\
\mathrm{HIV+}\end{array}$} & & \multirow[t]{2}{*}{$F^{a}$} & \multicolumn{2}{|c|}{$\%$} & \multirow[t]{2}{*}{$\chi^{2}$} \\
\hline & & HIV- & & $\mathrm{HIV+}$ & HIV- & \\
\hline \multicolumn{4}{|l|}{ Marital Status } & & & $7.02^{b}$ \\
\hline \multicolumn{2}{|c|}{ Married or Cohabitating } & & & $48 \%$ & $50 \%$ & \\
\hline \multicolumn{2}{|l|}{ Separated/Divorced } & & & $13 \%$ & $20 \%$ & \\
\hline \multicolumn{2}{|l|}{ Never Married } & & & $13 \%$ & $30 \%$ & \\
\hline \multicolumn{2}{|l|}{ Widowed } & & & $26 \%$ & $0 \%$ & \\
\hline Number of Children & 2.87 & 2.45 & $1.14^{\mathrm{a}}$ & & & \\
\hline Adult-to-child ratio $^{c}$ & 1.09 & 0.78 & $2.61^{\mathrm{a}}$ & & & \\
\hline
\end{tabular}

Age (in years) $\quad 12.59 \quad 13.05 \quad .462^{\mathrm{a}}$

Gender

Male

$39 \%$

$45 \%$

Female

$61 \% \quad 55 \%$

Note. ${ }^{\mathrm{a}}$ degrees of freedom for the $\mathrm{F}$ test are $(1,41) .{ }^{\mathrm{b}}$ trend $(p=.07)$; larger number of seropositive women are widowed $\left(X^{2}=6.06, p<.05\right) .{ }^{\mathrm{c}}$ number of adults over 18 years of age whom the mother named as currently living in the home divided by the number of children living in the home who were 18 year of age or younger.

$* p<.05$. 
Table 2

Psychosocial Adjustment for Children With HIV-Infected and Non-infected Mothers

\begin{tabular}{|c|c|c|c|c|c|}
\hline \multirow[b]{2}{*}{ Dependent Variables } & \multicolumn{2}{|c|}{$\mathrm{HIV}+$} & \multicolumn{2}{|c|}{ HIV- } & \multirow[b]{2}{*}{$\mathrm{F}$} \\
\hline & M & $\mathrm{SD}$ & $\mathrm{M}$ & SD & \\
\hline \multicolumn{6}{|l|}{ Externalizing Problems } \\
\hline Child Report & 54.86 & 9.92 & 47.40 & 8.69 & $6.67 *$ \\
\hline Mother Report & 53.73 & 13.95 & 53.00 & 8.27 & 0.04 \\
\hline Teacher Report & 55.89 & 10.70 & 53.93 & 11.06 & 0.27 \\
\hline \multicolumn{6}{|l|}{ Internalizing Problems } \\
\hline Child Report & 51.82 & 9.12 & 47.60 & 7.82 & 2.56 \\
\hline Mother Report & 49.73 & 12.63 & 52.60 & 7.69 & 0.77 \\
\hline Teacher Report & 52.74 & 9.19 & 48.29 & 10.45 & 1.68 \\
\hline \multicolumn{6}{|l|}{ Social Competence } \\
\hline Child Report & 3.03 & 0.75 & 3.21 & 0.71 & 0.65 \\
\hline Mother Report & 3.39 & 0.66 & 3.35 & 0.79 & 0.04 \\
\hline Teacher Report & 2.80 & 0.82 & 3.12 & 0.67 & 1.33 \\
\hline \multicolumn{6}{|l|}{ Cognitive Competence } \\
\hline Child Report & 2.83 & 0.66 & 2.68 & 0.60 & 0.61 \\
\hline Mother Report & 2.81 & 0.88 & 2.88 & 0.84 & 0.08 \\
\hline Teacher Report & 2.84 & 0.79 & 2.83 & 0.77 & 0.00 \\
\hline
\end{tabular}

${ }^{a}$ degrees of freedom for the $\mathrm{F}$ test varied from $(1,30)$ to $(1,41)$.

$* p<.05$. 
Table 3

Correlations Between Parenting and Child Psychosocial Variables

Parenting Variables

$\begin{array}{lllllllllll}\text { Child Variables } & \text { MCBQ } & \text { CCBQ } & \text { MINV } & \text { CINV } & \text { MPOS } & \text { CPOS } & \text { MMON } & \text { CMON } & \text { MINC } & \text { MFRI } \\ \text { Externalizing Problems } & & & & & & & & & & \\ \text { Child YSR } & .43^{* *} & .41^{* *} & -.24 & -.33^{*} & .10 & -.04 & .38^{*} & .17 & .13 & -.32^{*} \\ \text { Mother CBCL } & .68^{* * *} & .45^{* *} & -.17 & -.25 & -.19 & -.17 & .58^{* * *} & .15 & .54 * * * & -.25 \\ \text { Teacher TRF } & .39 * & .33 & .00 & -.24 & .07 & -.08 & .14 & .34 * & .19 & .06\end{array}$

Internalizing Problems

$\begin{array}{lllllllllll}\text { Child YSR } & .42 * * & .41 * * & -.08 & -.21 & .23 & -.08 & .23 & .28 & .23 & -.13 \\ \text { Mother CBCL } & .54 * * * & .52 * * * & -.15 & -.24 & -.25 & -.30 & .29 & .17 & .58 * * * & -.36 *\end{array}$

Social Competence

$\begin{array}{lllllllllll}\text { Child SPPC } & -.15 & -.28 & .27 & .16 & .18 & .39 * * & -.14 & -.12 & -.07 & .16 \\ \text { Mother PRS } & -.24 & -.44 * * & .29 & .17 & .31 * & .49 * * * & -.06 & -.05 & -.22 & .28\end{array}$


(Table 3, continued)

Correlations Between Parenting and Child Psychosocial Variables

Parenting Variables

\begin{tabular}{|c|c|c|c|c|c|c|c|c|c|c|}
\hline Social Competence & MCBQ & CCBQ & MINV & CINV & MPOS & CPOS & MMON & CMON & MINC & MFRI \\
\hline Teacher TRS & $-.53 * *$ & $-.62 * * *$ & .14 & .32 & .04 & .30 & $-.55^{* *}$ & $-.46 * *$ & $-.47 * *$ & -.04 \\
\hline \multicolumn{11}{|l|}{ Cognitive Competence } \\
\hline Child SPPC & -.07 & .01 & .20 & .27 & .17 & .27 & .09 & .12 & -.10 & .15 \\
\hline Mother PRS & $-.34 *$ & -.23 & $.44 * *$ & $.30 *$ & $.40 * *$ & .24 & $-.32 *$ & .15 & -.29 & $.51 * *$ \\
\hline Teacher TRS & -.15 & $-.42 *$ & -.16 & .32 & -.03 & .27 & -.12 & -.32 & -.24 & .13 \\
\hline
\end{tabular}

Note. $\mathrm{MCBQ}=$ mother report of relationship quality on Conflict Behavior Questionnaire; CCBQ = child report of relationship quality on CBQ, MINV = mother report of involvement on Alabama Parenting Questionnaire (APQ); CINV = child report of maternal involvement on APQ; MPOS = mother report of positive parenting on APQ; CPOS = child report of positive parenting on APQ; $\mathrm{MMON}=$ mother report of poor monitoring on APQ; CMON = child report of poor monitoring on APQ; MINC = mother report of inconsistent parenting on APQ; MFRI = mother report of family routines on Family Routines Inventory .

$* p<.05 . \quad * * p<.01 . \quad * * p<.001$. 